\title{
Nickel Sorption onto Chitosan - Silica Hybrid Aerogel from Aqueous Solution
}

\author{
Kelechi EBISIKE ${ }^{1, *}$, Afamefuna Elvis OKORONKWO ${ }^{2}$ and \\ Kenneth Kanayo ALANEME ${ }^{3,4}$
}

${ }^{I}$ Department of Engineering Materials, Institute Akure, Ondo, Nigeria

${ }^{2}$ Department of Chemistry, The Federal University of Technology Akure, Ondo, Nigeria

${ }^{3}$ Department of Metallurgical and Materials Engineering, The Federal University of Technology Akure, Ondo, Nigeria

${ }^{4}$ Centre for Nanoengineering and Tribocorrosion, School of Mining, Metallurgy and Chemical

Engineering, Faculty of Engineering and the Built Environment, University of Johannesburg,

South Africa

\section{("Corresponding author’s e-mail: kelebis@yahoo.com)}

Received: 30 January 2020, Revised: 3 July 2020, Accepted: 13 August 2020

\begin{abstract}
The utilization and efficiency of agricultural waste-derived chitosan-silica hybrid aerogel " $(\mathrm{CS})_{\mathrm{h}} \mathrm{A}$ " on nickel removal from aqueous solution was examined and optimum parameters for $\mathrm{pH}$, contact time, and initial ion concentration were determined during batch sorption system studies. Metal recovery was performed on the adsorbent using separately dilute concentrations of hydrochloric acid, acetic acid, ammonia, and sodium hydroxide solutions as eluents. The results generated were analyzed from kinetic and isotherm studies. The maximum $\mathrm{Ni}^{2+}$ adsorption of $99.78 \%$ was established at 60 min and $\mathrm{pH} 3$ in this study. The batch studies revealed that the percentage of nickel ion removal by the adsorbent decreased along with an increase in the initial $\mathrm{Ni}^{2+}$ ions concentration. The pseudo-second-order, the best fit of the kinetic model, has the values of its correlation coefficient " $R$ " ranging from 0.9 to 1 , whereas the Langmuir model which had the maximum monolayer adsorption capacity of $85.84 \mathrm{mg} \mathrm{g}^{-1}$, was the best isotherm in interpreting the sorption process and the calculated separation factor was higher than 0 but less than 1. Dilute hydrochloric acid $(0.1 \mathrm{M})$ was the best eluent in removing bound nickel ions $(55.63 \%)$ from $(\mathrm{CS})_{\mathrm{h}} \mathrm{A}$.
\end{abstract}

Keywords: Adsorbent, Chitosan - silica hybrid aerogel, Isotherm, Kinetic, Nickel

\section{Introduction}

Heavy metals exposure can bio-accumulate ending up permanently in the environment which could be a serious threat to humanity and the ecological system [1-3]. Metals like $\mathrm{Pb}^{2+}, \mathrm{Hg}^{2+}, \mathrm{Cd}^{2+}, \mathrm{Ni}^{2+}$, and $\mathrm{Cr}^{6+}$ can be highly toxic and their toxicity level is dependent on the metal type, valency, biological role, volume, and concentration [4]. Heavy metal ions released from nickel-related activities contaminate water $[5,6]$. This is a universal problem that is receiving attention globally [7] because of its hazardous effect on soil and water $[4,8]$.

According to WHO [9], nickel is of concern and its concentration must be reduced to a permissible level before released to the environment [7]; a concentration of nickel II above $0.02 \mathrm{mg} / \mathrm{L}$ can result in adverse health effects, including nausea, vomiting, diarrhea, pulmonary fibrosis, renal edema, and skin dermatitis [10,11]. It is, therefore, important to treat $\mathrm{Ni}$ (II) rich effluent before releasing it to the environment. Heavy metals toxicity has received high sensitization and hence research into technologies 
http://wjst.wu.ac.th

targeted at water cleanup. These technologies, like chemical precipitation, adsorption, reverse osmosis, ultra filtration, or ion exchange, have been investigated and some found to be expensive and generating harmful products $[10,12]$. However, adsorption proves to be less expensive, highly efficient and there is the ease in its design and usage [13-15]. Other merits of this technique involve low residue generation, easy metal recovery, and probability for reusability of sorbent [16]. Functional groups, e.g., carbonyl, amino, hydroxyl, phosphate, and sulfate existing in the adsorbent, can enhance the sorption of heavy metals likewise also the adsorption of sorbate unto the surface, pores, and complexion by the adsorbent [17].

Gottipati and Mishra [18] reported that surface area and pore volume are determining factors for sorption efficiency. Also, Gong et al. [19] reported that high surface area leads to metal ions adhering to the adsorbent. Biopolymer-based aerogels have continued to receive attention especially chitosan-based aerogels [20-22]. The presence of amine and hydroxyl groups in aerogels makes them highly effective for adhering to both anionic pollutants and heavy metal ions [23].

Besides, sorption capacity can be optimized by controlling their porosity and surface area [24]. Ebisike et al. [25] produced a high surface area chitosan-silica hybrid aerogel which possesses hydroxyl, carbonyl, amino, siloxane, and silanol groups which can boost the sorption of metal ions. Adsorption of cadmium using chitosan-silica hybrid aerogel had been reported as successful [26] but there has not been any report on the application of this aerogel for adsorption of nickel, which is a highly prevalent heavy metal in wastewaters in the study environment.

This work will provide information on the utilization of chitosan-silica hybrid aerogel in nickel ions adsorption. To obtain the optimum sorption conditions, the adsorption process will be analyzed on $\mathrm{pH}$, contact time, and initial nickel ion concentrations. Similarly, the desorption of the nickel ions bound by the adsorbent. Kinetic and sorption models will also be determined.

\section{Materials and methods}

\section{Adsorbent preparation}

Chitosan-silica hybrid aerogel $\left[(\mathrm{CS})_{\mathrm{h}} \mathrm{A}\right]$ was prepared following the method by Ebisike et al. [25]. Adsorption studies were carried out on nickel ion from an aqueous solution using the derived aerogel.

\section{pH profile studies}

Hydrochloric acid and sodium hydroxide were used to adjust the solutions to their respective labeled $\mathrm{pH} 1$ to 8 . The adsorbent was weighed into the 8 containers containing the solutions and then agitated for $6 \mathrm{~h}$, after which the resultant supernatant was collected for analysis.

\section{Contact time studies}

The $(\mathrm{CS})_{\mathrm{h}} \mathrm{A}$ was constantly agitated with $10 \mathrm{ml} \mathrm{Ni}^{2+}$ solution of different concentrations (that is, 10 , 20, 50, 75, 100 and $200 \mathrm{mg} / \mathrm{L}$ ). These solutions had been regulated to optimum $\mathrm{pH}$. Thereafter, 2 aliquots $(2 \mathrm{~mL})$ were removed from each suspension and transferred into uncontaminated beakers for studies at 5 , $10,15,30,60,120,180,240,300$, and $360 \mathrm{~min}$. The supernatants were gotten after centrifugation and then decanted into uncontaminated sample bottles for analysis.

\section{Metal recovery studies}

The $(\mathrm{CS})_{\mathrm{h}} \mathrm{A}$ was subjected to desorption studies using eluents of various concentrations $(0.1,0.05$, and $0.01 \mathrm{M}$ ) of hydrochloric acid, acetic acid, ammonia, and sodium hydroxide solutions, respectively. Sorbent material $(0.02 \mathrm{~g})$ was weighed and put in different beakers containing $10 \mathrm{~mL}$ of $50 \mathrm{mg} / \mathrm{L} \mathrm{Ni}^{2+}$ solutions which had already been regulated to $\mathrm{pH} 3$. This was stirred continuously for the optimum sorption time duration. The sorbent was centrifuged and the residue was introduced separately into $10 \mathrm{ml}$ of $0.01,0.05$, and $0.1 \mathrm{M}$ respectively for $\mathrm{HCl}, \mathrm{CH}_{3} \mathrm{COOH}, \mathrm{NH}_{3}$, and $\mathrm{NaOH}$. This was stirred up till optimum time and the supernatant was collected for analysis. 


\section{Results and discussion}

\section{Effect of pH}

Figure 1 shows the percentage of nickel ion bound by chitosan-silica hybrid aerogel. An optimum $\% \mathrm{Ni}^{2+}$ bound $(99.89 \%)$ was reached at $\mathrm{pH} 3$ with reduced nickel ion bound observed below this $\mathrm{pH}$ which could be as a result of more hydrogen ions surrounding the binding sites of the derived aerogel, hence making sorption to be unfavorable. Givianrad et al. [27] report that the more the $\mathrm{H}^{+}$ions on binding sites of the sorbent at lower $\mathrm{pH}$, the more the desorption of bound metals from the sites. It has been reported that when the ionic state of the amino and carboxyl groups of a sorbent is in a strongly acidic medium $(\mathrm{pH}<3)$, it will be protonated but becomes deprotonated at $\mathrm{pH} \geq 3$ [28-30]. Ebisike et al. [25] reported amino groups as part of the functional groups in the derived aerogel.

\section{Effect of initial concentration}

Sorption of initial nickel concentrations $(10-200 \mathrm{mg} / \mathrm{L})$ onto $(\mathrm{CS})_{\mathrm{h}} \mathrm{A}$ was carried out at constant contact time, temperature, and optimum $\mathrm{pH}$ and is presented in Figure 2. The $\% \mathrm{Ni}^{2+}$ ion removed is low at high initial concentration but increases when initial concentration reduces. Ebisike et al. [26] reported a similar trend with initial concentration studies during the adsorption studies of $\mathrm{Cd}^{2+}$ unto chitosan-silica hybrid aerogel. This increase in nickel ions removed after the initial ion concentration reduces may be linked to the formation of a mono ionic layer on the sorbent surface which may hinder the formation of an extra sorbate layer on the sorbent [31].

In addition, the adsorption sites ideally become saturated as the number of nickel ions removed from solution increases with increasing initial nickel concentration until a plateau-like shape is formed indicating that further nickel ions adsorption cannot occur [32]. The maximum concentration of $\mathrm{Ni}^{2+}$ removed at $10,20,50,75,100$, and $200 \mathrm{mg} / \mathrm{L}$ are $4.98,9.96,24.95,37.26,48.70$, and $85.84 \mathrm{mg} / \mathrm{g}$ respectively. These values are as presented in Table 1.

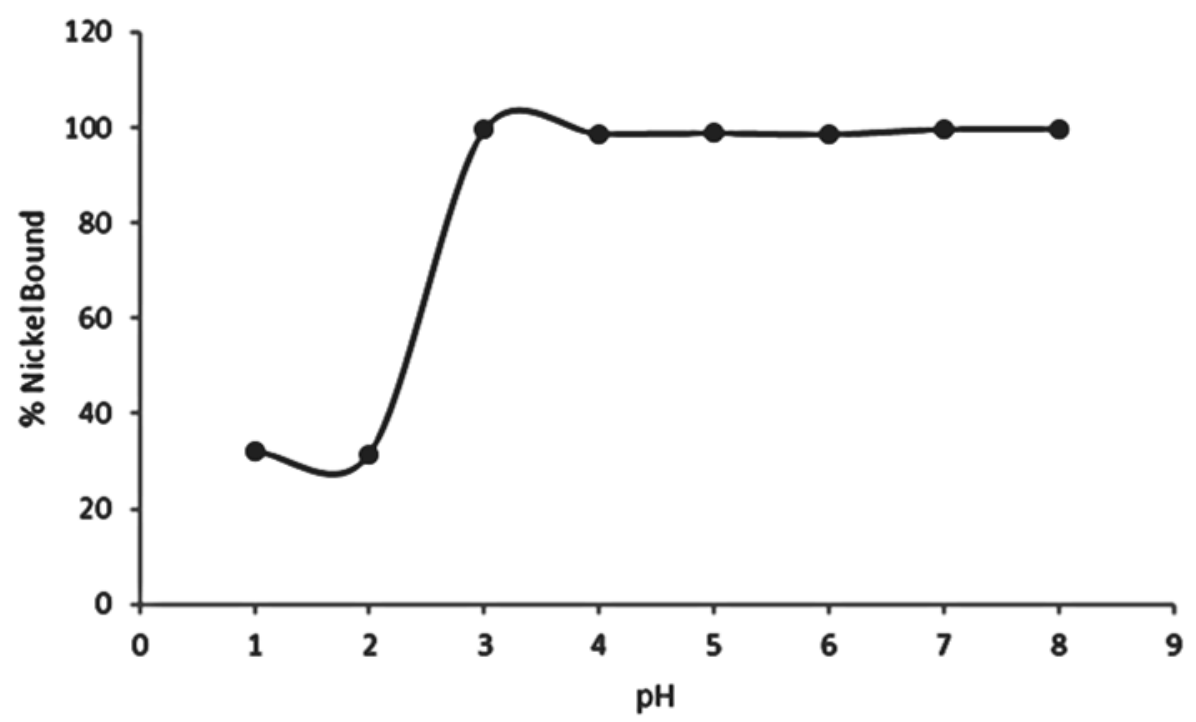

Figure 1 Plot of percentage nickel bound versus $\mathrm{pH}$ 
http://wjst.wu.ac.th

\section{Effect of contact time}

Figure 3 shows the results of $50 \mathrm{mg} / \mathrm{L}$ percent of nickel that is held on the surface of $(\mathrm{CS})_{\mathrm{h}} \mathrm{A}$ with respect to time. It was observed that $73.52 \% \mathrm{Ni}^{2+}$ was bounded by the adsorbent at the $5^{\text {th }}$ min of contact. This implies a $14.70 \% \mathrm{~min}^{-1}$ sorption rate. Such a sorption rate points to chemisorption as the possible reaction mechanism [16,33]. Also from the plot there looked to be adsorption and desorption of nickel ions on the chitosan-silica hybrid aerogel. The \% nickel removal rises as contact time increases until equilibrium is attained. Sixty min was achieved as the optimum sorption time for this study.

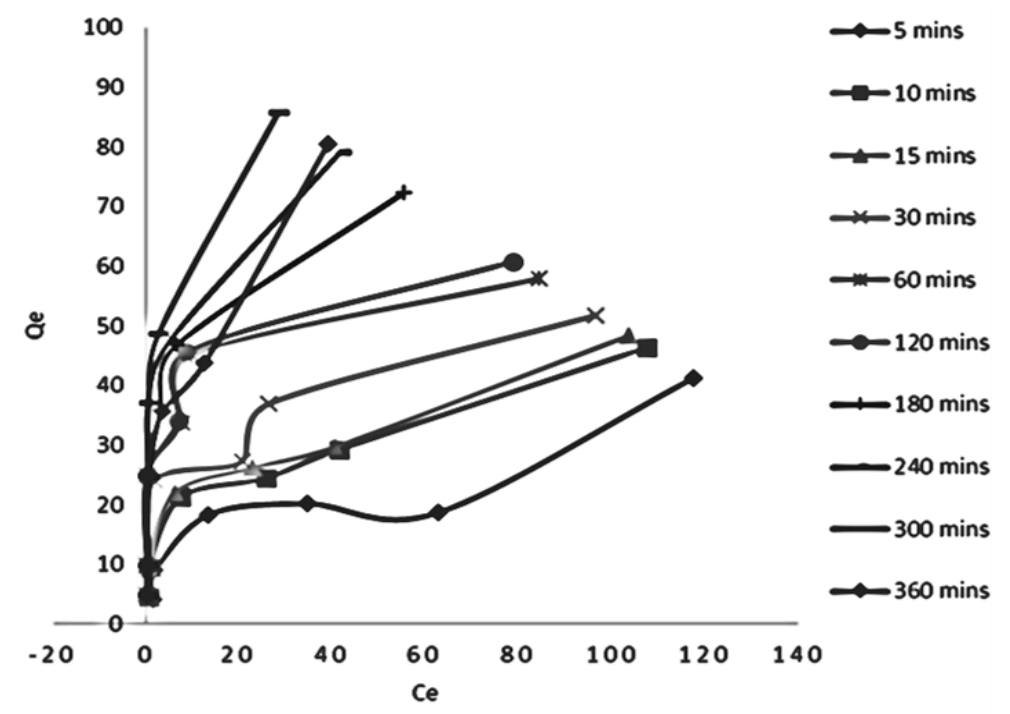

Figure 2 Plot of the amount of nickel adsorbed as a function of various concentration over a period of time.

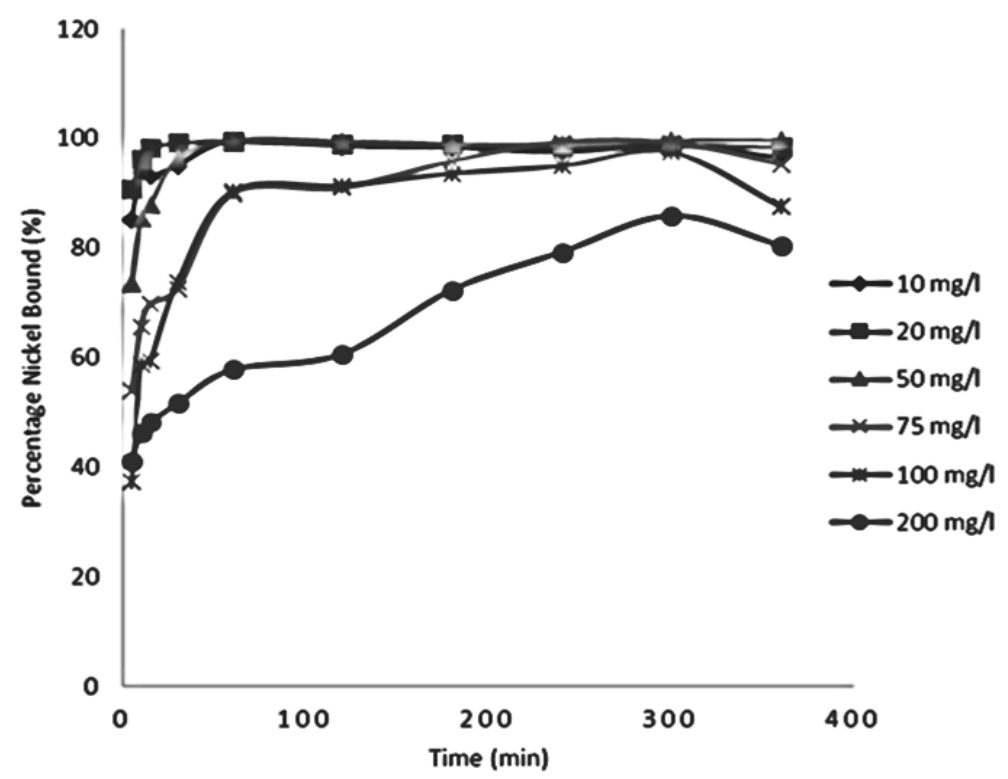

Figure 3 Plot of the percentage of various nickel bound concentration study as a function of time. 
http://wjst.wu.ac.th

Table 1 Kinetic parameters for nickel sorption onto chitosan - silica hybrid aerogel.

\begin{tabular}{|c|c|c|c|c|c|c|}
\hline Parameters & $10 \mathrm{ppm}$ & $20 \mathrm{ppm}$ & $50 \mathrm{ppm}$ & 75 ppm & 100 ppm & $200 \mathrm{ppm}$ \\
\hline \multicolumn{7}{|l|}{ Pseudo-first-order } \\
\hline $\mathrm{q}_{\mathrm{e} e \exp }\left(\mathrm{mg} \mathrm{g}^{-1}\right)$ & 4.9750 & 9.9550 & 24.9450 & 37.2550 & 48.7000 & 85.8400 \\
\hline $\mathrm{q}_{\mathrm{e} . \mathrm{cal}}\left(\mathrm{mg} \mathrm{g}^{-1}\right)$ & 0.3525 & 0.2311 & 3.0733 & 11.6332 & 13.1917 & 46.0045 \\
\hline $\mathrm{k}_{1}\left(\min ^{-1}\right)$ & 0.0053 & 0.0035 & 0.0182 & 0.0108 & 0.5595 & 0.0083 \\
\hline $\mathrm{R}^{2}$ & 0.3964 & 0.1557 & 0.8488 & 0.6771 & 0.0069 & 0.7940 \\
\hline \multicolumn{7}{|c|}{ Pseudo-second-order } \\
\hline $\mathrm{q}_{\mathrm{e} . \exp }\left(\mathrm{mg} \mathrm{g}^{-1}\right)$ & 4.9750 & 9.9550 & 24.9450 & 37.2550 & 48.7000 & 85.8400 \\
\hline $\mathrm{q}_{\text {e.cal }}\left(\mathrm{mg} \mathrm{g}^{-1}\right)$ & 4.8733 & 9.8522 & 25.0000 & 37.1747 & 46.9484 & 84.7458 \\
\hline $\mathrm{k}_{2}\left(\mathrm{~g} \mathrm{mg}^{-1} \min ^{-1}\right)$ & -1.8228 & -0.8959 & 0.0279 & 0.0042 & 0.0044 & 0.0006 \\
\hline $\mathrm{R}^{2}$ & 0.9994 & 1.0000 & 1.0000 & 0.9987 & 0.9947 & 0.9877 \\
\hline \multicolumn{7}{|c|}{ Intra-particle diffusion } \\
\hline $\mathrm{k}_{\text {id }}\left(\mathrm{mg} \mathrm{g}^{-1} \min ^{-1 / 2)}\right.$ & 0.0051 & 0.0004 & 0.2477 & 0.7958 & 1.4073 & 1.9679 \\
\hline $\mathrm{C}\left(\mathrm{mg} \mathrm{g}^{-1}\right)$ & 4.6339 & 9.5234 & 20.2480 & 23.3590 & 25.6090 & 30.5750 \\
\hline $\mathrm{R}^{2}$ & 0.7743 & 0.6273 & 0.8609 & 0.8909 & 0.7810 & 0.9786 \\
\hline \multicolumn{7}{|l|}{ Elovich } \\
\hline$A_{E}\left(g g^{-1}\right)$ & 8.9847 & 8.6505 & 0.7768 & 0.2578 & 0.1617 & 0.1002 \\
\hline $\mathrm{B}_{\mathrm{E}}\left(\mathrm{mg} \mathrm{g}^{-1} \min ^{-1}\right)$ & $8.09 \mathrm{E}+15$ & $9.98 \mathrm{E}+33$ & 1778354 & 197.5908 & 57.2926 & 84.5465 \\
\hline $\mathrm{R}^{2}$ & 0.2496 & 0.4561 & 0.7833 & 0.9504 & 0.8751 & 0.9177 \\
\hline
\end{tabular}

The sorption process was subjected to pseudo-first ${ }^{\mathrm{t}}$-order or Lagergen kinetic, pseudo-second-order, intra-particle diffusion, and Elovich kinetic models. Table 1 gives the different kinetic model parameters for different test conditions used in explaining the batch sorption process.

The applicability of the pseudo-first-order or Lagergen kinetic model is a result of the high value of the correlation coefficient $\left(\mathrm{R}^{2}\right)$ obtained from the line plot. The correlation coefficient value for 50 and $200 \mathrm{mg} / \mathrm{L}$ is high whereas poor linearity is observed for other studied nickel concentrations which record low values as shown in Figure 4. Hence, there is a deviation of this sorption process from this model. Also, to support the applicability of this model, the value of the experimental equilibrium uptake must be equivalent to the calculated, but in this case, they are far apart as seen in Table 1, and therefore cannot be used to interpret the kinetics. Information for this model (Figure 5) and the derived parameter values (Table 1) shows that the $\mathrm{R}^{2}$ value is above 0.9 and to some extent unity for some studied concentration. This means that this model can explain the adsorption process. 


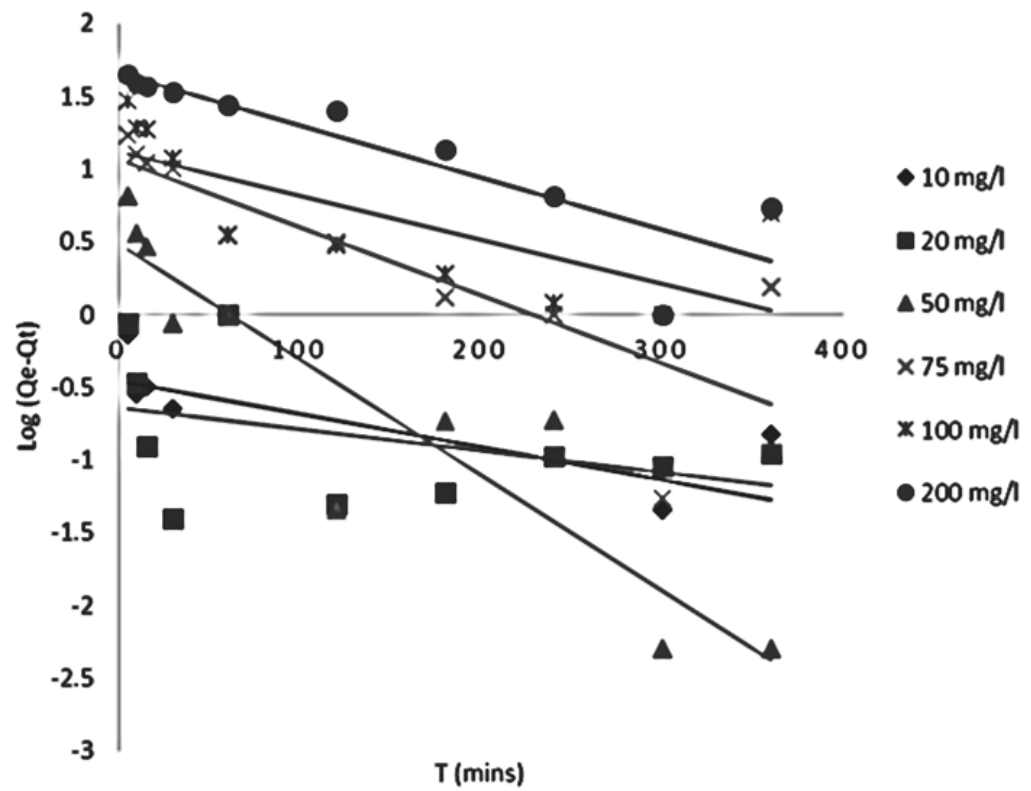

Figure 4 Pseudo-first-order plot for derived chitosan-silica hybrid aerogel in a nickel solution.

Moreover, the acceptability of the high value of the $R^{2}$ in explaining the sorption process is justified when there is a close relationship between the test $\left(\mathrm{q}_{\mathrm{e} \text { exp }}\right)$ and calculated $\left(\mathrm{q}_{\mathrm{e} . \mathrm{cal}}\right)$ equilibrium adsorptions. Also, with this model, the rate-determining step is controlled by chemisorption having forces that share or interchange electrons amongst $\mathrm{Ni}^{2+}$ and $(\mathrm{CS})_{\mathrm{h}} \mathrm{A}$. The values of $\mathrm{k}_{2}$ for 10 and $20 \mathrm{mg} / \mathrm{L}$ are negative which could imply that the rate of chemical sorption is reducing as time increases. Some literature (Table 2) provides information concerning the Pseudo-second-order kinetic model [34-36] for the adsorption of $\mathrm{Ni}^{2+}$ present in an aqueous solution.

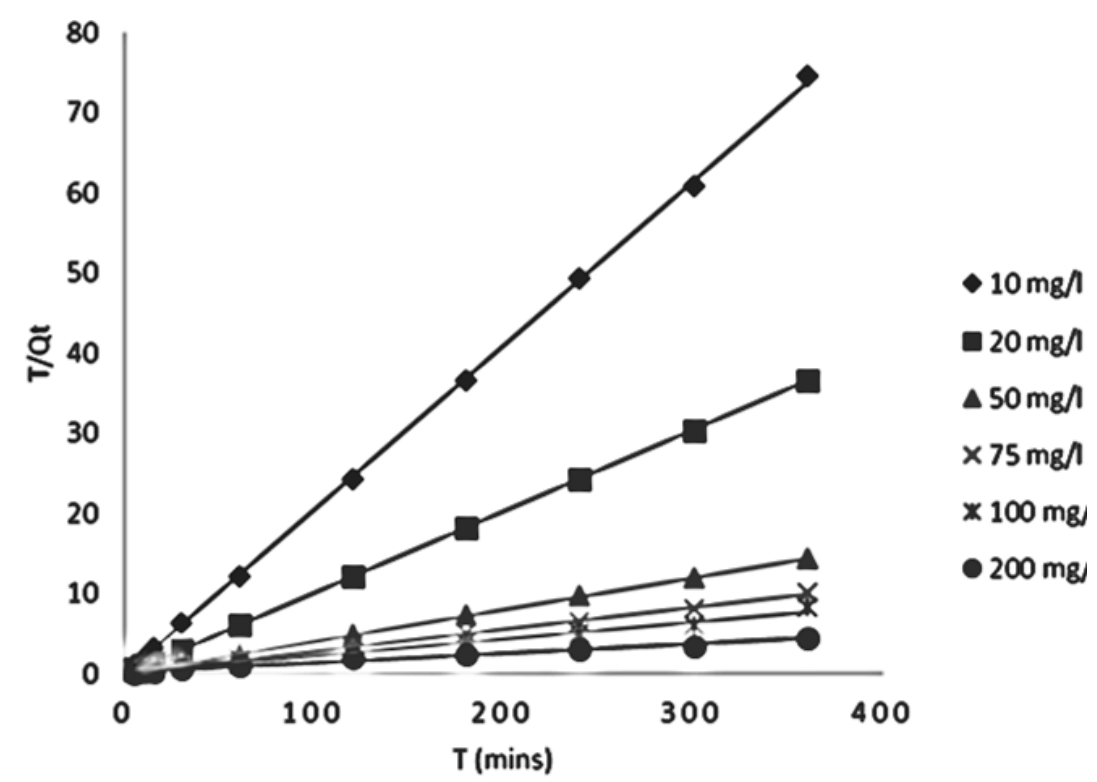

Figure 5 Pseudo-second-order plot for derived chitosan - silica hybrid aerogel in nickel solution. 
http://wjst.wu.ac.th

Table 1 and Figure 6 give the parameters for intra-particle diffusion and its plot respectively. Analyzing the plot, it was observed that 50,75, 100, and $200 \mathrm{mg} / \mathrm{L}$ are not completely linear. There are 3 distinct linear parts to explain the sorption steps which are; instantaneous adsorption observed at the initial stage, intra-particle diffusion as the $2^{\text {nd }}$ stage, whereas in the last stage there is a decline in intraparticle diffusion as a result of very low adsorbate concentration left in solution [37,38]. This last stage is what was observed for both the 10 and $20 \mathrm{mg} / \mathrm{L}$ sorption process. From the plot, the straight lines did not pass through the origin which means that intra-particle diffusion cannot be said to be the only ratelimiting step [37,39].

Figure 7 is the Elovich plot for the sorption process. The correlation coefficients for 50, 75, 100, and $200 \mathrm{mg} / \mathrm{L}$ are greater than 0.8 which is also a good fit to the model and shows the significance of diffusional rate-limiting step in nickel sorption onto $(\mathrm{CS})_{\mathrm{h}} \mathrm{A}$, even though the test data at low concentrations of 10 and $20 \mathrm{mg} / \mathrm{L}$ cannot explain this model. Also, an increase in the initial concentration of the solution from 10 to $200 \mathrm{mg} / \mathrm{L}$ causes the desorption constant to reduce.

The adsorption process which explains how metal ions concentration relates to adsorbents were also subjected to Langmuir, Freundlich, Temkin, and Dubinin-Raduskevich Isotherm. It can also improve the experimental conditions set to actualize optimum uptake of metal $[40,41]$ as observed in the result reported.

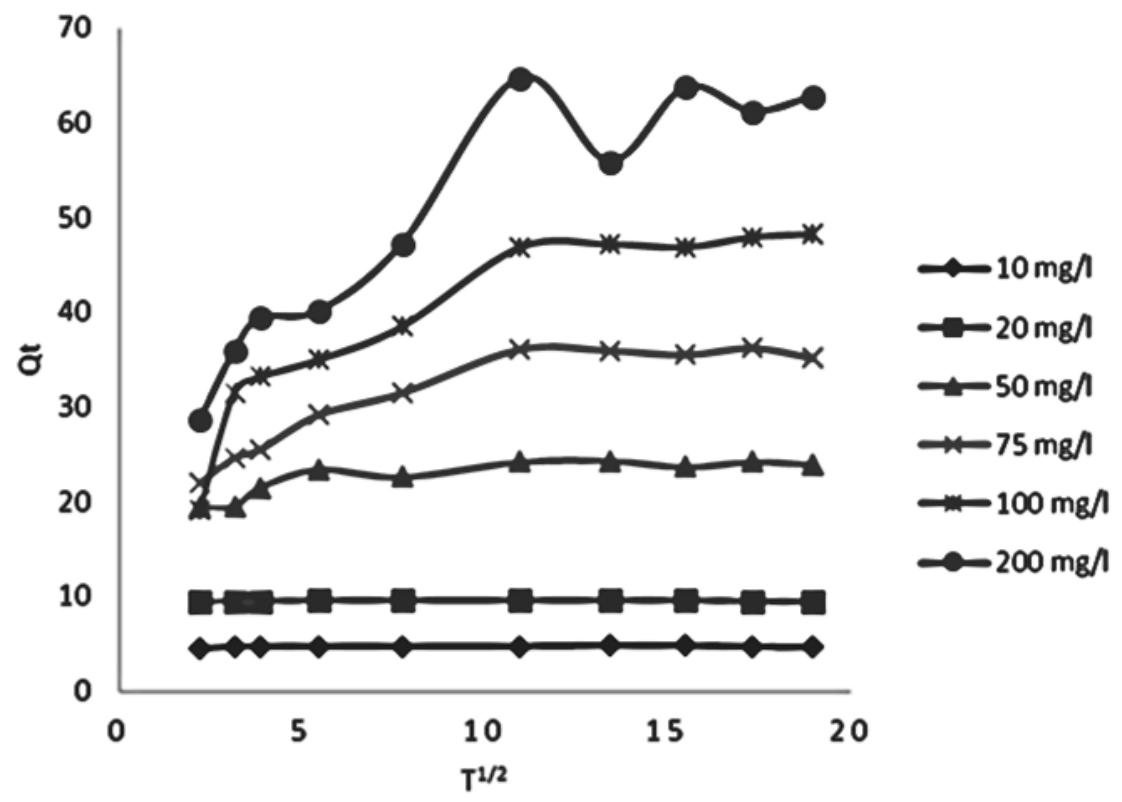

Figure 6 Intra-particle diffusion model plot for derived chitosan-silica hybrid aerogel in a nickel solution. 
http://wjst.wu.ac.th

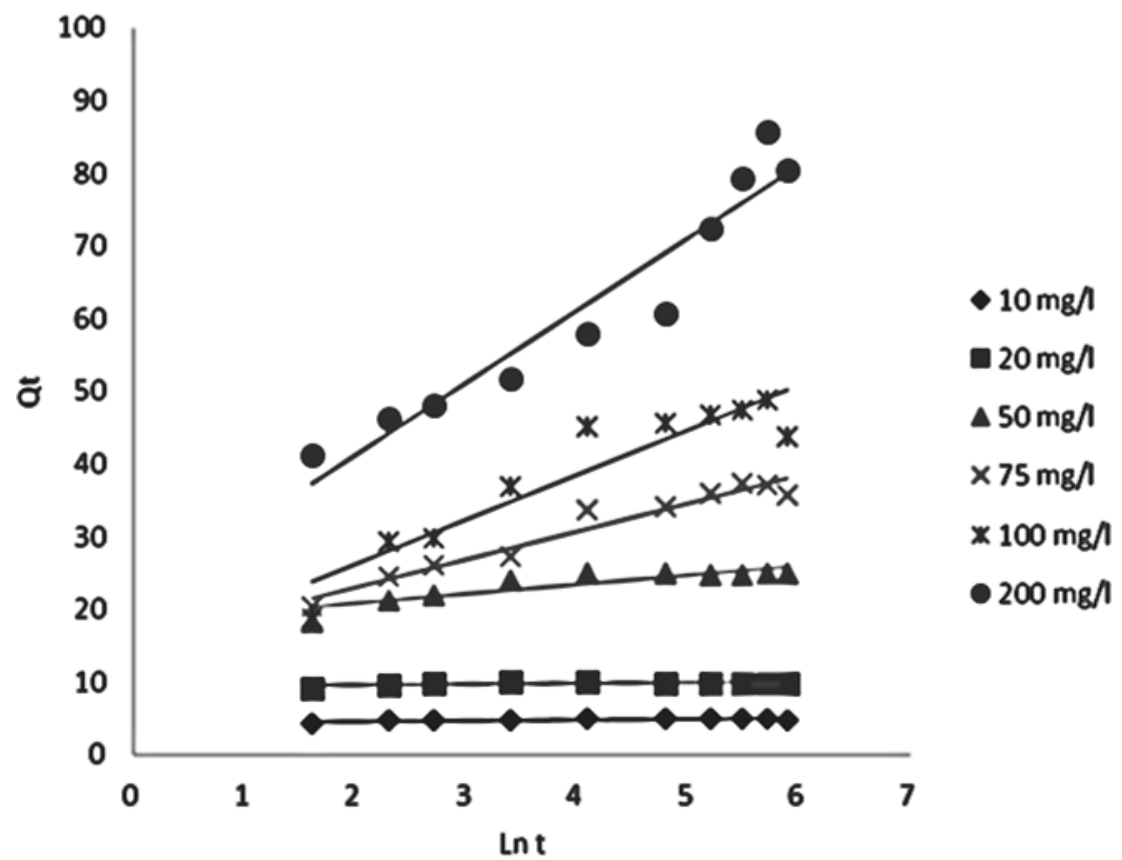

Figure 7 Elovich model plot for derived chitosan - silica hybrid aerogel in a nickel solution.

Table 2 Comparison for the removal of $\mathrm{Ni}^{2+}$ by different adsorbents.

\begin{tabular}{lclcl}
\hline \multicolumn{1}{c}{ Adsorbent } & $\begin{array}{c}\text { Sorption } \\
\text { capacity }(\mathbf{m g} / \mathbf{g})\end{array}$ & Kinetic model & $\begin{array}{c}\text { Isotherm } \\
\text { model }\end{array}$ & Reference \\
\hline $\begin{array}{l}\text { Lignocellulose/ } \\
\text { montmorillonite } \\
\text { (LNC/MMT) } \\
\text { nanocomposite }\end{array}$ & 94.86 & Pseudo-second-order & Langmuir & Zhang and Wang, 2015 \\
$\begin{array}{l}\text { Activated Carbon Olive } \\
\text { Stone }\end{array}$ & 77.00 & Pseudo-second-order & Freundlich & Ahmed et al., 2019 \\
$\begin{array}{l}\text { Citric acid modified } \\
\text { Ceiba pentandra hulls }\end{array}$ & 34.34 & Pseudo-second-order & Langmuir & Ramana et al., 2012 \\
$\begin{array}{l}\text { Amine-functionalized } \\
\text { silica aerogel }\end{array}$ & 40.32 & - & Langmuir & Sertsing et al., 2018 \\
$\begin{array}{l}\text { Ulva lactuca biomass } \\
\text { Modified holly sawdust }\end{array}$ & 38.28 & Pseudo-second-order & Langmuir & Long et al., 2018 \\
$\begin{array}{l}\text { Tamarid bark } \\
\text { Modified Riverbed Sand }\end{array}$ & 22.47 & Pseudo-second-order & Langmuir & Samarghandi, et al., 2011 \\
Mustard oil cake & 15.34 & Pseudo-second-order & Langmuir & Zang et al., 2010 \\
& 0.86 & Pseudo-first-order & Langmuir & Abdullah and Prasad, 2010 \\
& 2.761 & Pseudo-second-order & Temkin & Khan et al., 2012 \\
& 2.956 & Pseudo-second-order & Temkin & \\
& 3.208 & Pseudo-second-order & Freundlich &
\end{tabular}


http://wjst.wu.ac.th

\begin{tabular}{|c|c|c|c|c|}
\hline Adsorbent & $\begin{array}{c}\text { Sorption } \\
\text { capacity }(\mathrm{mg} / \mathrm{g})\end{array}$ & Kinetic model & $\begin{array}{c}\text { Isotherm } \\
\text { model }\end{array}$ & Reference \\
\hline Strains of Yarrowia & & & Langmuir and & Shinde et al., 2012 \\
\hline lipolytica; & 95.33 & Pseudo-second-order & Freundlich & \\
\hline NCIM 3589 & 85.44 & Pseudo-second-order & & \\
\hline NCIM 3590 & & & & \\
\hline $\begin{array}{l}\text { Calcium Alginate/ H- } \\
\text { magadiite-D2EHPA } \\
\text { (CAM-D2EHPA) }\end{array}$ & 44 & Pseudo-second-order & Langmuir & Attar et al., 2019 \\
\hline Peat & 61.27 & Pseudo-second-order & Langmuir & Przemysław et al., 2015 \\
\hline $\begin{array}{l}\text { Callinectes sapidus } \\
\text { biomass }\end{array}$ & 29.15 & Pseudo-second-order & Freundlich & Foroutan et al., 2019 \\
\hline $\begin{array}{l}\text { Magnetic activated } \\
\text { carbon/chitosan } \\
\text { composite (MACCS) } \\
\text { beads }\end{array}$ & 108.70 & Pseudo-second-order & Langmuir & Le et al., 2019 \\
\hline $\begin{array}{l}\text { Activated carbon from } \\
\text { sewage sludge }\end{array}$ & 11.52 & Pseudo-second-order & Freundlich & Khelifi, et al.,2018 \\
\hline $\begin{array}{l}\text { Chitin/lignin hybrid } \\
\text { material }\end{array}$ & 70.41 & Pseudo-second-order & Langmuir & Bartczak et al., 2017 \\
\hline $\begin{array}{l}\text { Chitosan-silica hybrid } \\
\text { aerogel }\end{array}$ & 85.84 & Pseudo-second-order & Langmuir & Present study \\
\hline
\end{tabular}

Figures 8 - 11 and Table 3 are representations of investigations of sorption isotherms of various initial $\mathrm{Ni}^{2+}$ concentrations. While most of the correlation coefficient values of the sorption isotherms are high, that of Langmuir (that is: 0.748 - 0.999) could be considered best in interpreting what is happening in the system. In other words, the sorption process is homogeneous [42] and every other adsorption stops after a single layer of ion had been formed on the surface of the adsorbent. The Dimensionless separation factor ' $R_{L}$ ' was found within the range from $0.011-0.682$ which is an indication of the applicability of Langmuir isotherm on the sorption of $\mathrm{Ni}^{2+}$ onto this adsorbent. The $\mathrm{R}_{\mathrm{L}}$ values reduce as the initial nickel ion concentration increases, indicating more favorable adsorption at a higher $\mathrm{Ni}^{2+}$ concentration. Maximum sorption can be considered for optimization purposes because it points out the best uptake capacity of adsorbent [43] The optimum nickel adsorption values ' $Q_{\max }$ ' obtained at initial concentration were recorded from 39.22 to $131.60 \mathrm{mg} / \mathrm{g}$. Table 2 shows a similar report from the literature supporting the Langmuir model for nickel ion sorption from aqueous solution [44-46]. 


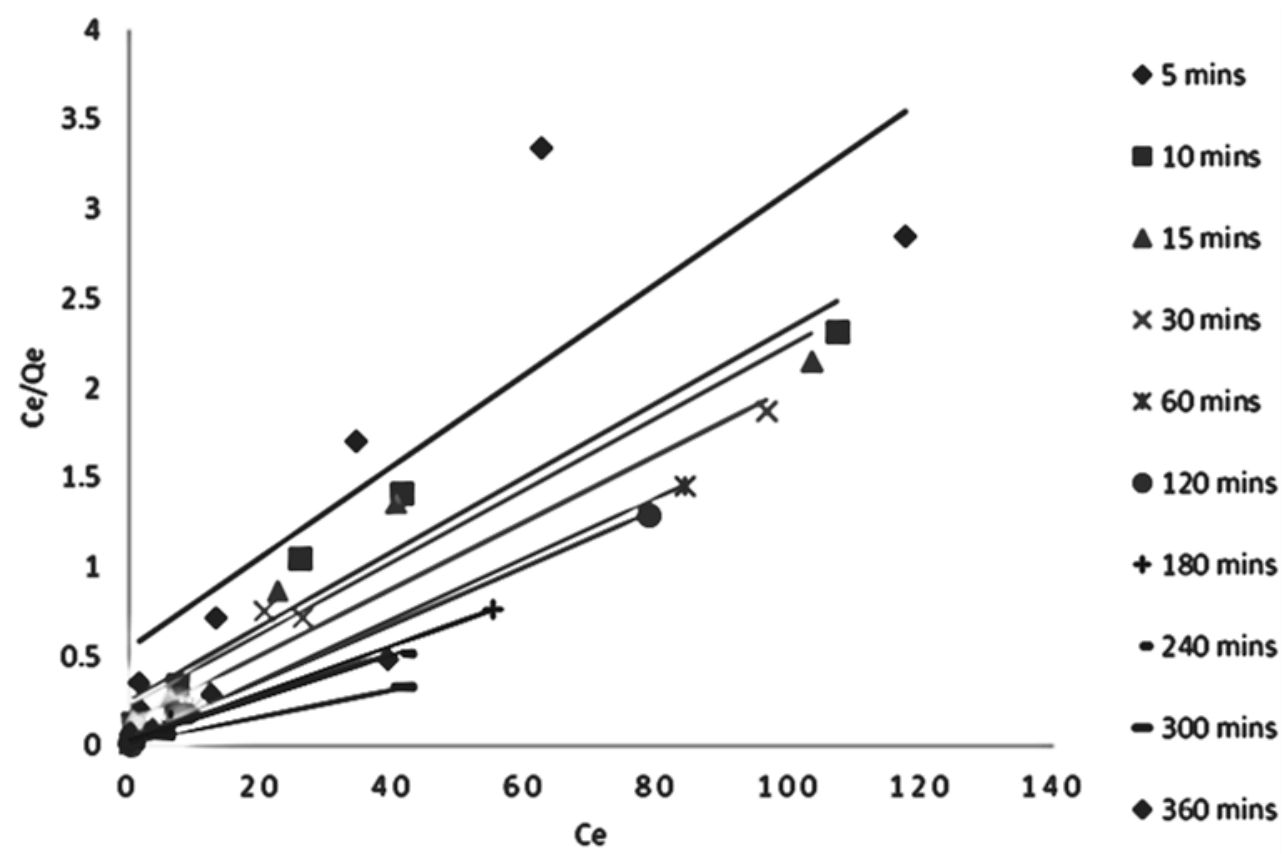

Figure 8 Langmuir isotherm plot for derived chitosan-silica hybrid aerogel in a nickel solution.

Freundlich isotherm has its correlation coefficient values in the range $(0.596-0.919)$ of which 240 , 300 and $360 \mathrm{~min}$ have their $\mathrm{R}^{2}$ values as $0.647,0.619$, and 0.596 , respectively to be moderately correlated while other studied times are highly correlated. Also, a Freundlich constant ' $n$ ' which is a measure of the deviation of adsorption from linearity is above 1 but less than 10 implying also the application of Freundlich isotherm interpreting the sorption process. It was reported that adsorption intensity is more heterogeneous as it approaches 0 [47], while it is considered homogeneous if it tends to unity [16]. The slope $1 / \mathrm{n}$ lies above zero but less than one and all values are closer to 0 as contact time increases, hence, it is more homogenous. 
http://wjst.wu.ac.th

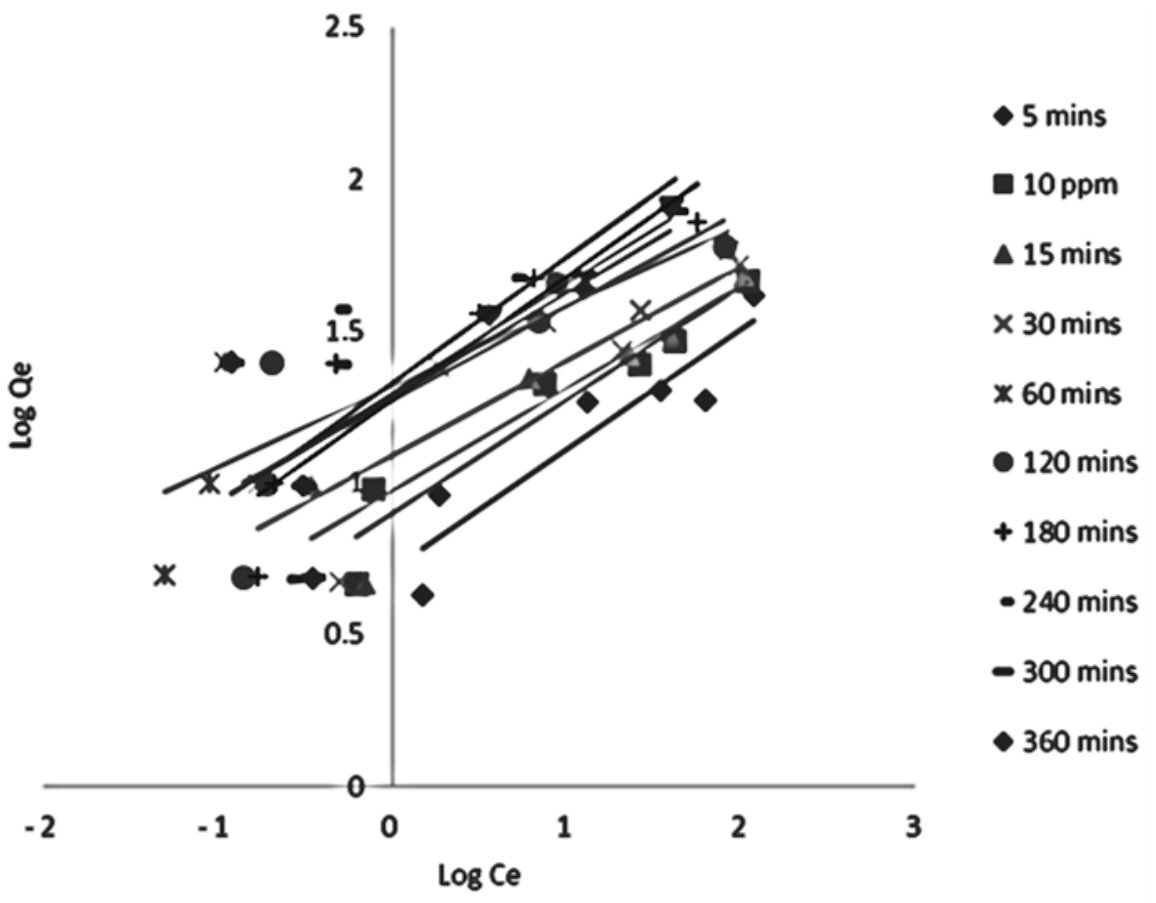

Figure 9 Freundlich Isotherm plot for derived chitosan-silica hybrid aerogel in a nickel solution.

Foroutan et al. [48] when using Callinectes sapidus biomass to remove nickel ions from aqueous stream predicted Freundlich as the best model in interpreting the adsorption process. Similarly, Freundlich isotherm was also predicted to be the best fit when nickel ion was adsorbed by Activated carbon olive stone [49].

The $\mathrm{R}^{2}$ value of Temkin falls in the range of 0.867 to 0.987 , indicating that they are highly correlated. This implies that the interaction between the $(\mathrm{CS})_{\mathrm{h}} \mathrm{A}$ and the $\mathrm{Ni}^{2+}$ as well as the adsorption process relates to surface coverage [37].

Dubinin Raduskevick isotherm model with its $\mathrm{R}^{2}$ value falling in the range of 0.844 to 0.953 could interpret the adsorption process, unlike the lowly correlated values. The calculated mean free energy of adsorption ' $\mathrm{E}$ ' for all the time frames studied is less than $8 \mathrm{~kJ} / \mathrm{mol}(0.032-3.540 \mathrm{~kJ} / \mathrm{mol})$. This process relates to physisorption.

A comparison of different adsorbents with respect to sorption efficiency achieved for removal of nickel ions is presented in Table 2. In this study, chitosan-silica hybrid aerogel showed better sorption capacity for $\mathrm{Ni}^{2+}$ as compared to other adsorbents. It should be noted that the sorption of nickel onto chitosan-silica hybrid aerogel is a function of the adsorbent, the radius of the spherical shell of the solvent molecule formed around the $\mathrm{Ni}^{2+}$ ion, the equilibrium constant for hydrolysis reaction, electronegativity, and relative binding affinity [50,51]. Hence, these factors might competitively and effectively influence the sorption of other heavy metals onto the adsorbent having been successfully utilized for cadmium removal [26]. This is a sound basis for this research which aims at investigating the remover efficiency of $\mathrm{Ni}^{2+}$ by chitosan-silica hybrid aerogel. 


\section{http://wjst.wu.ac.th}

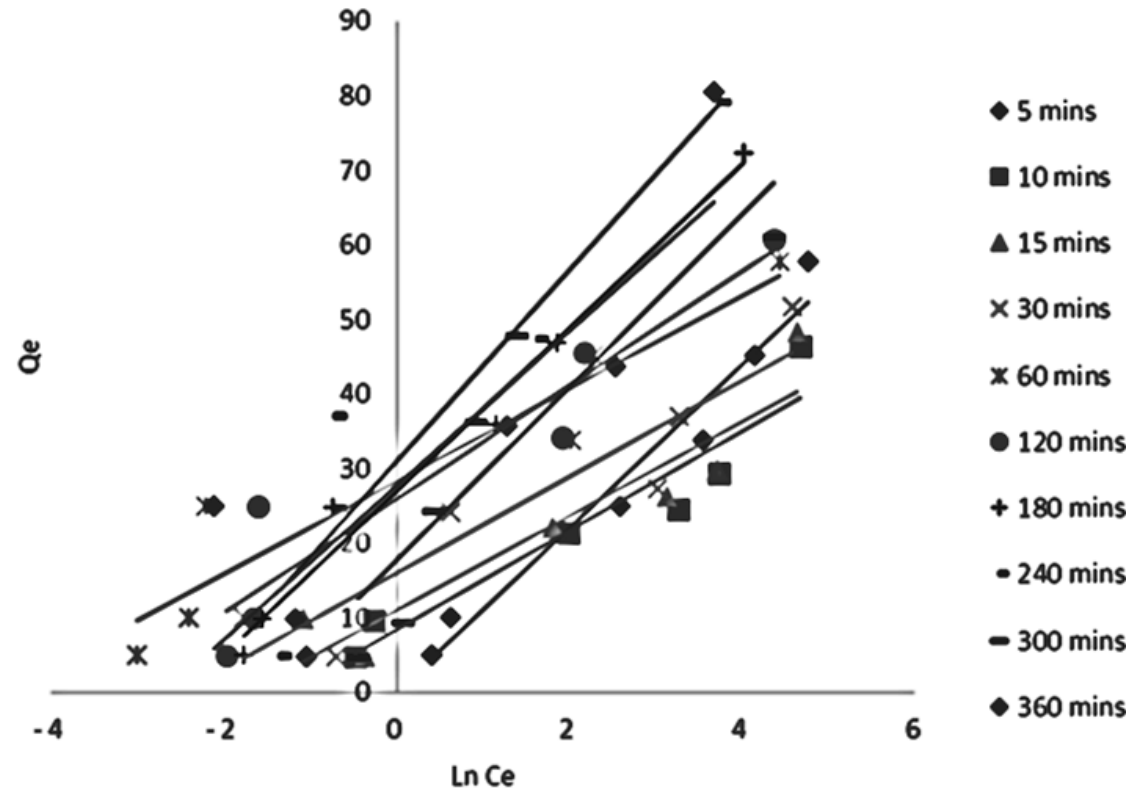

Figure 10 Temkin isotherm plot for derived chitosan - silica hybrid aerogel in a nickel solution.

Table 3 Isotherm parameters of a different model for nickel ions sorption onto chitosan-silica hybrid aerogel.

\begin{tabular}{|c|c|c|c|c|c|c|c|c|c|c|c|}
\hline \multirow{2}{*}{\multicolumn{2}{|c|}{ Parameters }} & \multicolumn{10}{|c|}{ Time (min) for Ni adsorption onto chitosan-silica hybrid Aerogel } \\
\hline & & \multirow{2}{*}{$\begin{array}{c}\mathbf{5} \\
39.22\end{array}$} & \multirow{2}{*}{$\frac{10}{48.08}$} & \multirow{2}{*}{$\frac{15}{49.51}$} & \multirow{2}{*}{$\frac{\mathbf{3 0}}{53.48}$} & \multirow{2}{*}{$\begin{array}{c}\mathbf{6 0} \\
57.47\end{array}$} & \multirow{2}{*}{\begin{tabular}{r|}
$\mathbf{1 2 0}$ \\
62.11
\end{tabular}} & \multirow{2}{*}{\begin{tabular}{r|}
$\mathbf{1 8 0}$ \\
75.19
\end{tabular}} & \multirow{2}{*}{$\begin{array}{r}\mathbf{2 4 0} \\
83.33\end{array}$} & \multirow{2}{*}{\begin{tabular}{r|}
$\mathbf{3 0 0}$ \\
83.10
\end{tabular}} & \multirow{2}{*}{\begin{tabular}{r|}
$\mathbf{3 6 0}$ \\
84.75
\end{tabular}} \\
\hline Langmuir & $\mathrm{q}_{\max }(\mathrm{mg} / \mathrm{g})$ & & & & & & & & & & \\
\hline & $\mathrm{k}_{\mathrm{L}}(\mathrm{L} / \mathrm{mg})$ & 1.832 & 3.945 & 4.521 & 7.418 & 22.57 & 27.62 & 31.65 & 35.21 & 34.81 & 18.59 \\
\hline & $\mathrm{R}_{\mathrm{L}}$ & & & & & & & & & & \\
\hline & $10 \mathrm{mg} / \mathrm{L}$ & 0.682 & 0.549 & 0.523 & 0.419 & 0.203 & 0.184 & 0.192 & 0.191 & 0.175 & 0.313 \\
\hline & $20 \mathrm{mg} / \mathrm{L}$ & 0.517 & 0.379 & 0.354 & 0.265 & 0.113 & 0.101 & 0.106 & 0.106 & 0.096 & 0.186 \\
\hline & $50 \mathrm{mg} / \mathrm{L}$ & 0.300 & 0.196 & 0.180 & 0.126 & 0.049 & 0.043 & 0.045 & 0.045 & 0.041 & 0.084 \\
\hline & $75 \mathrm{mg} / \mathrm{L}$ & 0.222 & 0.140 & 0.127 & 0.088 & 0.033 & 0.029 & 0.031 & 0.031 & 0.028 & 0.057 \\
\hline & $100 \mathrm{mg} / \mathrm{L}$ & 0.176 & 0.109 & 0.099 & 0.067 & 0.025 & 0.022 & 0.023 & 0.023 & 0.021 & 0.044 \\
\hline & $200 \mathrm{mg} / \mathrm{L}$ & 0.097 & 0.057 & 0.052 & 0.035 & 0.013 & 0.011 & 0.012 & 0.012 & 0.011 & 0.022 \\
\hline & $\mathrm{R}^{2}$ & 0.748 & 0.937 & 0.937 & 0.923 & 0.999 & 0.996 & 0.997 & 0.993 & 0.995 & 0.934 \\
\hline \multirow[t]{4}{*}{ Freundlich } & $\begin{array}{l}\mathrm{k}_{\mathrm{F}}(\mathrm{mg} / \mathrm{g}) \mathrm{L} / \\
\mathrm{mg}\end{array}$ & 5.202 & 7.989 & 9.395 & 12.32 & 20.79 & 18.66 & 18.79 & 21.35 & 19.86 & 19.24 \\
\hline & $\mathrm{n}$ & 2.535 & 2.677 & 2.948 & 3.195 & 3.755 & 3.198 & 2.447 & 2.416 & 2.777 & 2.901 \\
\hline & $\mathrm{L} / \mathrm{n}$ & 0.395 & 0.374 & 0.339 & 0.313 & 0.266 & 0.313 & 0.409 & 0.414 & 0.360 & 0.345 \\
\hline & $\mathrm{R}^{2}$ & 0.853 & 0.919 & 0.84 & 0.770 & 0.764 & 0.734 & 0.833 & 0.647 & 0.619 & 0.596 \\
\hline \multirow[t]{4}{*}{ Temkin } & $\mathrm{B}(\mathrm{mg} / \mathrm{L})$ & 10.93 & 6.636 & 6.320 & 6.450 & 6.215 & 7.642 & 10.99 & 12.86 & 11.63 & 10.36 \\
\hline & $\mathrm{b}_{\mathrm{T}}$ & 229.1 & 377.1 & 396.0 & 388.0 & 402.7 & 3.398 & 227.7 & 194.6 & 215.3 & 241.6 \\
\hline & $\mathrm{A}_{\mathrm{T}}(\mathrm{L} / \mathrm{mg})$ & 1.021 & 3.539 & 5.697 & 12.07 & 94.54 & 327.5 & 11.72 & 11.14 & 4.566 & 14.72 \\
\hline & $\mathrm{R}^{2}$ & 0.987 & 0.974 & 0.980 & 0.867 & 0.902 & 0.899 & 0.982 & 0.900 & 0.813 & 0.763 \\
\hline \multirow{4}{*}{$\begin{array}{l}\text { Dubinin- } \\
\text { Radushkevich }\end{array}$} & $\mathrm{q}_{\max }(\mathrm{mg} / \mathrm{g})$ & 23.71 & 33.34 & 25.88 & 27.42 & 47.23 & 48.25 & 51.39 & 72.97 & 51.75 & 49.49 \\
\hline & $\mathrm{k}_{\mathrm{ad}}\left(\mathrm{mg} / \mathrm{kj}^{2}\right)$ & $-1 E-6$ & $-2 \mathrm{E}-7$ & $-1 E-7$ & $-6 \mathrm{E}-8$ & $-4 E-8$ & $-7 \mathrm{E}-8$ & $-9 \mathrm{E}-8$ & $-2 \mathrm{E}-7$ & -5.00 & $-6 E-7$ \\
\hline & $\mathrm{E}(\mathrm{Kj} / \mathrm{mol})$ & 0.707 & 1.58 & 2.24 & 2.89 & 3.54 & 2.67 & 2.36 & 1.58 & 0.032 & 0.913 \\
\hline & $\mathrm{R}^{2}$ & 0.843 & 0.728 & 0.482 & 0.413 & 0.884 & 0.816 & 0.947 & 0.900 & 0.953 & 0.938 \\
\hline
\end{tabular}


http://wjst.wu.ac.th

\section{Metal recovery studies}

Figures 12 is a plot showing the effect of various concentrations $(0.1,0.05$, and $0.01 \mathrm{M})$ of eluents on the recovery of $\mathrm{Ni}^{2+}$ present on chitosan-silica hybrid aerogel respectively. $\mathrm{HCl}(0.1 \mathrm{M})$ was most effective in desorbing $\mathrm{Ni}^{2+}$ from $(\mathrm{CS})_{\mathrm{h}} \mathrm{A}$ amongst other eluents that were applied for the study. This is because the maximum removal of bound $\mathrm{Ni}^{2+}$ from this adsorbent by $\mathrm{HCl}, \mathrm{CH}_{3} \mathrm{COOH}, \mathrm{NH}_{3}$, and $\mathrm{NaOH}$ was recorded as 55.63, 34.72, 1.21, and $1.14 \%$ respectively at $60 \mathrm{~min}$. The acidic eluents cause the derived aerogel surface to be protonated, hence, the nickel bound ions will be desorbed [52,53] whereas the alkaline eluents had a very low effect on the desorption of nickel ions. This low effect may be attributed to more hydroxyl groups formed in the solution making more openings at the active sites which support electrostatic exchanges amongst cations and sorbent surface.

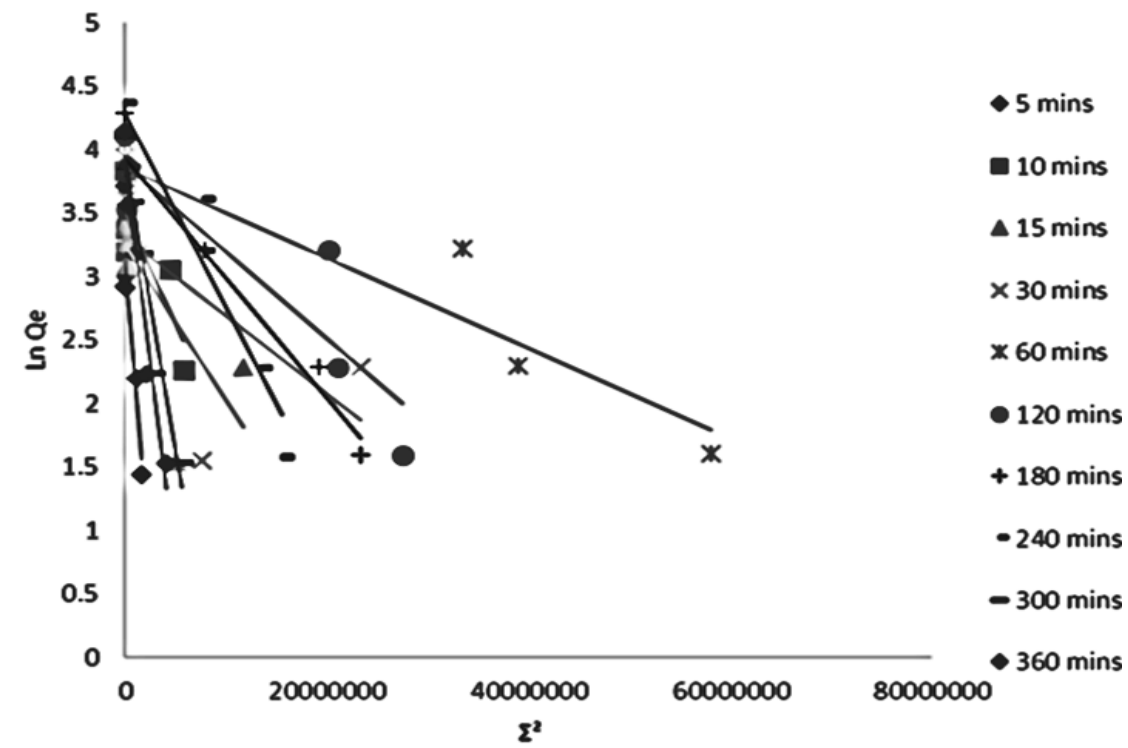

Figure 11 Dubinin-Radushkevich (D-R) isotherm plot for derived chitosan-silica hybrid aerogel in a nickel solution.

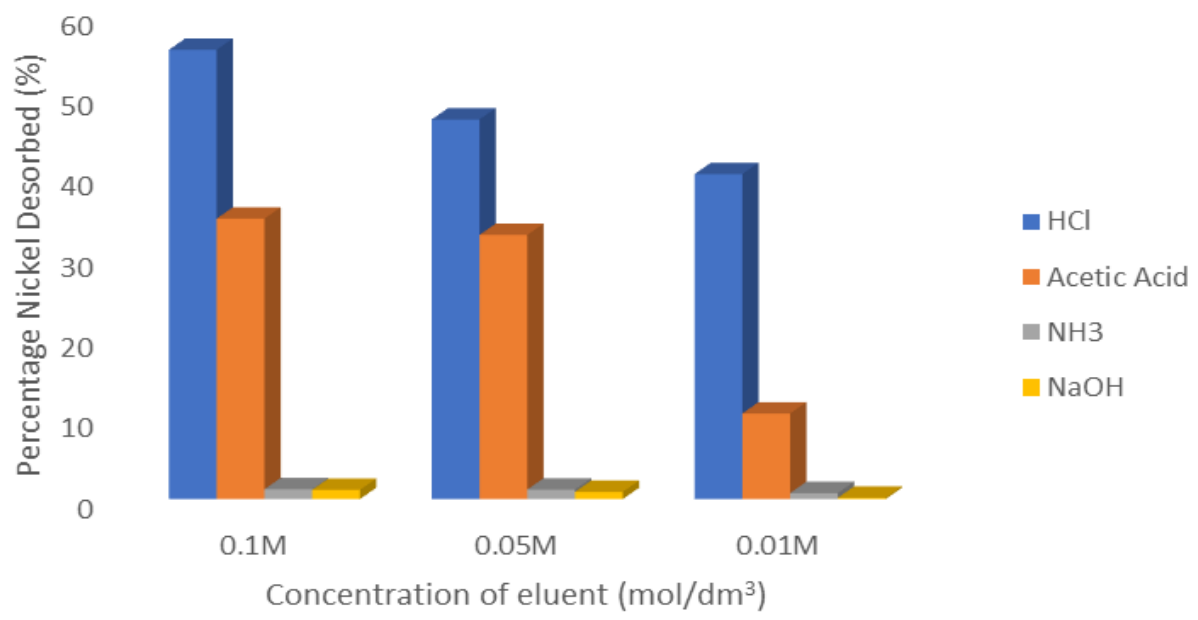

Figure 12 Plot of the percentage of $50 \mathrm{ppm}$ nickel desorbed. 
http://wjst.wu.ac.th

\section{Conclusions}

With an optimum $\mathrm{pH}$ of 3 and sorption contact time of $60 \mathrm{~min}$, Nickel ions (99.78\%) were maximally recovered from aqueous solution by $(\mathrm{CS})_{\mathrm{h}} \mathrm{A}$. When the initial nickel ion concentration was raised from $10-200 \mathrm{mg} / \mathrm{L}$, the number of nickel ions removed from the solution ranged from 4.98 $85.84 \mathrm{mg} / \mathrm{g}$. Langmuir isotherm and Pseudo-second-order kinetics best explain the adsorption process. The separation factor also indicates that the sorption process is favorable under the Langmuir model. Dilute hydrochloric acid $(0.1 \mathrm{M})$ was more effective in recovering bound nickel ions $(55.63 \%)$ from the derived aerogel. Hence, nickel ions can be effectively recovered from and by chitosan-silica hybrid aerogel when utilized in contaminated water.

\section{References}

[1] H Zhang, X Yu, L Chen and J Geng. Investigation of radionuclide ${ }^{63} \mathrm{Ni}(\mathrm{II})$ sorption on ZSM-5 zeolite. J. Radioanal. Nucl. Chem. 2010; 286, 249-58.

[2] MA Abdullah and AGD Prasad. Biosorption of nickel (II) from aqueous solutions and electroplanting wastewater using tamarind (Tamarindusindica L.). Aust. J. Basic Appl. Sci. 2010; 4, 3591-601.

[3] AE Burakov, EV Galunin, IV Burakova, AE Kucherova, S Agarwal, AG Tkachev and VK Gupta. Adsorption of heavy metals on conventional and nanostructured materials for wastewater treatment purposes: A review. Ecotoxicol. Environ. Saf. 2018; 148, 702-12.

[4] ME Ossman and M Abdelfattah. Response surface methodology for optimising the operating conditions of nickel (II) adsorption. J. Environ. Eng. Sci. 2015; 10, 27-33.

[5] SM Turp, B Eren and A Ates. Prediction of adsorption efficiency for the removal of nickel (II) ions by zeolite using artificial neural network (ANN) approach. Fresen. Environ. Bull. 2011; 20, 315865 .

[6] S Yadav, V Srivastava, S Banerjee, F Gode and YC Sharma. Studies on the removal of Ni (II) ions from aqueous solutions using modified riverbed sand. Environ. Sci. Pollut. Res. 2013; 20, 558-67.

[7] X Zhang and X Wang. Adsorption and desorption of Nickel (II) ions from aqueous solution by a lignocellulose/montmorillonite nanocomposite. Plos One 2015; 10, e0117077.

[8] T Motsi, NA Rowson and MJH Simmons. Kinetic studies of the removal of heavy metals from acid mine drainage by natural zeolite. Int. J. Miner. Process. 2011; 101, 42-49.

[9] World Health Oraganization. Guidelines for drinking water quality. Vol. I. World Health Organization, Geneva, 2010, p. 281-8.

[10] DKV Ramana, DHK Reddy, BN Kumar, Y Harinath and K Seshaiah. Removal of nickel from aqueous solutions by citric acid modified Ceiba pentandra hulls: Equilibrium and kinetic studies, Can. J. Chem. Eng. 2012; 90, 111-9.

[11] MA Khan, M Ngabura, TSY Choong, H Masood and LA Chuah. Biosorption and desorption of nickel on oil cake: Batch and column studies. Bioresource Tech. 2012; 103, 35-42.

[12] NR Shinde, AV Bankar, AR Kumar and SS Zinjarde. Removal of Ni (II) ions from aqueous solutions by biosorption onto two strains of Yarrowia lipolytica. J. Environ. Manag. 2012; 102, 115-24.

[13] VT Le, MU Dao, HS Le, DL Tran, VD Doan and HT Nguyen. Adsorption of Ni (II) ions by magnetic activated carbon/chitosan beads prepared from spent coffee grounds, shrimp shells and green tea extract. Environ. Tech. 2019; 41, 2817-32.

[14] M Ahmaruzzaman. Role of fly ash in the removal of organic pollutants from wastewater. Energ. Fuel. 2009; 23, 1494-511.

[15] M Ahmaruzzaman and VK Gupta. Rice husk and its ash as low-cost adsorbents in water and wastewater treatment. Ind. Eng. Chem. Res. 2011; 50, 13589-613.

[16] A Gładysz-Płaska, E Skwarek, TM Budnyak and D Kołodyńska. Metal ions removal using nano oxide pyrolox $^{\mathrm{TM}}$ material. Nanoscale Res. Lett. 2017; 12, 95. 
http://wjst.wu.ac.th

[17] AK Meena, GK Mishra, PK Rai, C Rajagopal and PN Nagar. Removal of heavy metal ions from aqueous solutions using carbon aerogel as an adsorbent. J. Hazard. Mater. 2005; 122, 161-70.

[18] R Gottipati and S Mishra. Process optimization of adsorption of $\mathrm{Cr}(\mathrm{VI})$ on activated carbons prepared from plant precursors by a two-level full factorial design. Chem. Eng. J. 2010; 160, 99107.

[19] J Gong, X Wang, X Shao, S Yuan, C Yang, and X Hu. Adsorption of heavy metal ions by hierarchically structured magnetite-carbonaceous spheres. Talanta 2012; 101, 45-52.

[20] A Bhatnagar and M Sillanpää. Applications of chitin- and chitosan - derivatives for the detoxification of water and wastewater: A short review. Adv. Colloid Interface Sci. 2009; 152, 2638.

[21] M Vakili, M Rafatullah, B Salamatinia, AZ Abdullah, MH Ibrahim, KB Tan, Z Gholami and P Amouzgar. Application of chitosan and its derivatives as adsorbents for dye removal from water and wastewater: A review. Carbohydr. Polymer. 2014; 113, 115-30.

[22] S Olivera, HB Muralidhara, K Venkatesh, VK Guna, K Gopalakrishna and Y Kumar. Potential applications of cellulose and chitosan nanoparticles/composites in wastewater treatment: A review. Carbohydr. Polym. 2016; 153, 600-18.

[23] G Crini and PM Badot. Application of chitosan, a natural aminopolysaccharide, for dye removal from aqueous solutions by adsorption processes using batch studies: A review of recent literature. Progr. Polym. Sci. 2008; 33, 399-47.

[24] M Salzano de Luna, C Ascione, C Santillo, L Verdolotti, M Lavorgna, GG Buonocore, R Castaldo, $\mathrm{G}$ Filippone, $\mathrm{H}$ Xia and L Ambrosio. Optimization of dye adsorption capacity and mechanical strength of chitosan aerogels through crosslinking strategy and graphene oxide addition. Carbohydr. Polym. 2019; 211, 195-203.

[25] K Ebisike, AE Okoronkwo and KK Alaneme. Synthesis and characterization of chitosan-silica hybrid aerogel using sol-gel method. J. King Saud Univ. Sci. 2020; 32, 550-4.

[26] K Ebisike, AE Okoronkwo and KK Alaneme. Adsorption of Cd (II) on chitosan silica hybrid aerogel from aqueous solution. Environ. Tech. Innovat. 2019; 14, 100377.

[27] MH Givianrad, M Rabani, M Saber-Tehrani, P Aberoomand-Azar and MH Sabzevari. Preparation and characterization of nanocomposite, silica aerogel, activated carbon and its adsorption properties for Cd (II) ions from aqueous solution. J. Saudi Chem. Soc. 2013; 17, 329-35.

[28] L Pan, Z Wang, Q Yang and R Huang. Efficient removal of lead, copper and cadmium ions from water by a porous calcium alginate/graphene oxide composite aerogel. Nanomaterials 2018; 8, 957.

[29] ZQ Wang, YG Huang, M Wang, GH Wu, TM Geng, YG Zhao and AG Wu. Macroporous calcium alginate aerogel as sorbent for $\mathrm{Pb}^{2+}$ removal from water media. J. Environ. Chem. Eng. 2016; 4, 3185-92.

[30] YG Huang and ZQ Wang. Preparation of composite aerogels based on sodium alginate, and its application in removal of $\mathrm{Pb}^{2+}$ and $\mathrm{Cu}^{2+}$ from water. Int. J. Biol. Macromol. 2018; 107, 741-7.

[31] P Govindaraj, P Sivasamy and J Rejinis. Effective removal of heavy metal ions from a binary mixture by adsorption on activated coconut shell carbon using complexing agent. J. Chem Pharmaceut. Res. 2012; 4, 286-93.

[32] D Balarak, J Jaafari, G Hassani, Y Mahdavi, I Tyagi, S Agarwal and VK Gupta. The use of low-cost adsorbent (Canola residues) for the adsorption of methylene blue from aqueous solution: Isotherm, kinetic and thermodynamic studies. Colloid. Interface Sci. Comm. 2015; 7, 16-9.

[33] C Pang, Y Liu, X Cao, R Hua, C Wang and C Li. Adsorptive removal of uranium from aqueous solution using chitosan-coated attapulgite. J. Radioanal. Nucl. Chem. 2010; 286,185-93.

[34] O Khelifi, M Nacef and AM Affoune. Nickel (II) Adsorption from aqueous solutions by physicochemically modified sewage sludge. Iran J. Chem. Chem. Eng. 2018; 37, 73-87.

[35] J Long, X Huang, X Fan, Y Peng and J Xia. Effective adsorption of nickel (II) with Ulva lactuca dried biomass: Isotherms, kinetics and mechanisms. Water Sci. Tech. 2018; 78, 156-64.

[36] MR Samarghandi, S Azizian, MS Siboni, SJ Jafari and S Rahimi. Removal of divalent nickel from aqueous solutions by adsorption onto modified holly sawdust: Equilibrium and kinetics. Iran J. Environ. Health Sci. Eng. 2011; 8, 181-8. 
http://wjst.wu.ac.th

[37] H Qianlin, L Xiaoqing, X Lian, H Chao, Z Hairong, L Mutan, T Lanlan and C Xinde. Equilibrium, kinetic and thermodynamic studies of acid soluble lignin adsorption from rice straw hydrolysate by a self-synthesized macro/mesoporous resin. RSC Adv. 2017; 7, 23896-906.

[38] $\mathrm{H}$ Zaghouane-Boudiaf and $\mathrm{M}$ Boutahala. Adsorption of 2,4,5-trichlorophenol by organomontmorillonites from aqueous solutions: kinetics and equilibrium studies. Chem. Eng. J. 2011; 170, 120-6.

[39] FC Wu, RL Tseng and RS Juang. Adsorption of dyes and phenols from water on the activated carbons prepared from corncob wastes. Environ. Tech. 2001; 22, 205-13.

[40] KA Emmanuel, KA Ramaraju and KS Rao. Removal of Mn (II) from aqueous solutions using bombax malabaricum fruit shell substrate. J. Chem. 2007; 4, 419-27.

[41] Z Belattmania, S Tahiri, R Zrid, A Reani, S Elatouani, H Loukili, M Hassouani, ME Krati, F Bentiss and B Sabour. Bioremoval of hexavalent chromium from aqueous solutions by the brown seaweed dictyopterispolypodioides. Res. J. Environ. Toxicol. 2015; 9, 218-30.

[42] K Attar, H Demey, D Bouazza and AM Sastre. Sorption and desorption studies of Pb (II) and Ni (II) from aqueous solutions by a new composite based on alginate and magadiite materials. Polymers $2019 ; \mathbf{1 1}, 340$.

[43] YG Bermudez, ILR Rico, E Guibal, MC de Hoces and MA Martin-Lara. Biosorption of hexavalent chromium from aqueous solution by Sargassum muticum brown alga. Application of statistical design for process optimization. Chem. Eng. J. 2012; 183, 68-76.

[44] S Sertsing, T Chukeaw, S Pengpanich and B Pornchuti. Adsorption of nickel and chromium ions by amine functionalized silica aerogel. MATEC Web Conf. 2018; 156, 03014.

[45] P Bartczak, L Klapiszewski, M Wysokowski, I Majchrzak, W Czernicka, A Piasecki, H Ehrlich and $\mathrm{T}$ Jesionowski. Treatment of model solutions and wastewater containing selected hazardous metal ions using a chitin/lignin hybrid material as an effective sorbent. J. Environ. Manage. 2017; 204, 300-10.

[46] B Przemysław, N Małgorzata, K Łukasz, K Natalia, K Małgorzata, B Monika, W Marcin, Z Jakub, C Filip and J Teofil. Removal of nickel (II) and lead (II) ions from aqueous solution using peat as a low-cost adsorbent: A kinetic and equilibrium study. Arab. J. Chem. 2015; 11, 1209-22.

[47] A Asfaram, M Ghaedi, S Agarwal, I Tyagi and VK Gupta. Removal of basic dye Auramine-O by $\mathrm{ZnS}: \mathrm{Cu}$ nanoparticles loaded on activated carbon optimization of parameters using response surface methodology with central composite design. RSC Adv. 2015; 5, 18438-50.

[48] R Foroutan, R Mohammadi, S Farjadfard, H Esmaeili, M Saberi, S Sahebi, S Dobaradaran and B Ramavandi. Characteristics and performance of $\mathrm{Cd}, \mathrm{Ni}$, and $\mathrm{Pb}$ bio-adsorption using Callinectes sapidus biomass: Real wastewater treatment. Environ. Sci. Pollut. Res. 2019; 26, 6336-47.

[49] AM Ahmed, AE Ali and AH Ghazy. Adsorption separation of nickel from wastewater by using olive stones. Adv. J. Chem. A 2019; 2, 79-93.

[50] A Sdiri, T Higashi, R Chaabouni and F Jamoussi. Competitive removal of heavy metals from aqueous solutions by montmorillonitic and calcareous clays. Water Air Soil Pollut. 2012; 223, 1191204.

[51] A Sdiri, M Khairy, S Bouaziz and S El-Safty. A natural clayey adsorbent for selective removal of lead from aqueous solutions. Appl. Clay Sci. 2016; 126, 89-97.

[52] D Kołodynska, J Krukowska and P Thomas. Comparison of sorption and desorption studies of heavy metal ions from biochar and commercial active carbon. Chem. Eng. J. 2017; 307, 353-63.

[53] A Bogusz, P Oleszczuk and R Dobrowolski. Application of laboratory prepared and commercially available biochars to adsorption of cadmium, copper and zinc ions from water. Bioresource Tech. $2015 ; 196,540-9$. 